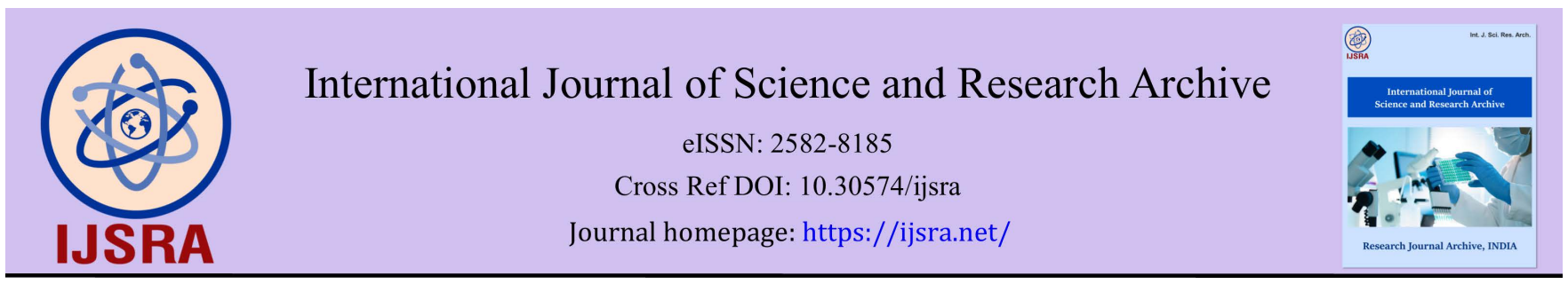

(RESEARCh ARTicle)

\title{
Acceleration of micropropagation procedure of Bambusa nutans: A commercially important bamboo species
}

\author{
Yogeshwar Mishra ${ }^{1,}{ }^{*}$, Jay Prakash Mishra ${ }^{2}$ and Munmun Mitra 1 \\ ${ }^{1}$ Institute of Forest Productivity, Ranchi, Jharkhand, India. \\ 2 Tropical Forest Research Institute, Jabalpur, Madhya Pradesh, India.
}

International Journal of Science and Research Archive, 2022, 05(01), 079-085

Publication history: Received on 01 January 2022; revised on 10 February 2022; accepted on 12 February 2022

Article DOI: https://doi.org/10.30574/ijsra.2022.5.1.0032

\begin{abstract}
The present communication described an accelerated, efficient and reproducible in vitro propagation procedure for large-scale multiplication of Bambusa nutans Roxb. The nodal segments (12-18 $\mathrm{mm})$ collected from secondary branches of superior clump in the month of April reported enhanced multiple shoot formation (7-8) when implanted on Murashige \& Skoog semi solid medium supplemented with $10 \mu \mathrm{M}$ BA (6-Benzylaminopurine). These axillary shoot cultures pass through ten subculture cycle on liquid medium of $10 \mu \mathrm{M}$ BA. The cluster of two axillary shoots transferred to liquid MS medium containing $10 \mu \mathrm{M}$ BA+ $7.0 \mu \mathrm{M}$ NAA ( $\alpha$-Naphthaleneacetic acid) produced a maximum of 14.5 multiple shoots after 20 days of inoculation. Rooting of $100 \%$ of shoots was achieved in excised propagules when transferred to $1 / 2$ MS medium supplemented with $30 \mu \mathrm{M}$ NAA. A two-step hardening procedure of in vitro raised plants ensured $100 \%$ survival. Macroproliferation was carried out in hardened plants after 4 months registered threefold number of plants in polythene bags. The field transferred plants were reported with $100 \%$ survival with prolific new shoot formation and growth.
\end{abstract}

Keywords: B nutans; Field transfer; Macroproliferation; Nodal explants

\section{Introduction}

Bambusa nutans Wall. ex Munro a medium-sized woody bamboo and naturally distributed throughout bamboo growing states of India, is multipurpose bamboo species with ecological and economic importance. It is one of the twelve high yielding bamboos for large scale plantation prioritized by the National Bamboo Mission (NBM) India. It flowers gregariously after 30-60 years and constitutes an ideal species for micropropagation. Several micropropagation protocols of Bambusa nutans have been developed reporting higher shoot multiplication and rooting success. Yadav et al. ${ }^{1}$ reported 3.18-fold shoot multiplication on MS liquid medium enriched with 31.06 $\mu \mathrm{M}$ BAP+ $2.18 \mu \mathrm{M}$ IAA and rooting up to $77 \%$ on MS medium with $25 \mu \mathrm{M}$ IBA from 10-year-old field grown clumps. Negi \& Saxena ${ }^{2}$ reported slightly enhanced shoot multiplication of 3.5-fold in the medium with $3.2 \mu \mathrm{M}$ BA+ $2.32 \mu \mathrm{M}$ KIN (Kinetin) $+0.98 \mu \mathrm{M}$ IBA (Indole3 -Butyric Acid) but with optimum rooting success of $100 \%$ on half MS medium with $9.8 \mu \mathrm{M}$ IBA+2.85 $\mu \mathrm{M}$ IAA+2.68 $\mu \mathrm{M}$ NAA. Further, Sharma \&Sarma ${ }^{3}$ and Mudoiet al. ${ }^{4}$ reported 11 -fold shoot multiplication on MS medium with $1 \mathrm{mg} / \mathrm{l}$ BA and BAP $(0.5 \mathrm{mg} / \mathrm{L})$ and $0.1 \mathrm{mg} / \mathrm{l} \alpha$-naphthalene acetic acid, respectively, whereas rooting success was achieved more than $80 \%$ in NAA supplemented medium. In the present study an effort was made to up-scale these earlier published protocols and thus, an efficient in vitro propagation method was developed that could meet the demand of $B$. nutans plants en masse.

\footnotetext{
${ }^{*}$ Corresponding author: Yogeshwar Mishra

Institute of Forest Productivity, Ranchi, Jharkhand, India.
} 


\subsection{Abbreviations}

BA- 6-Benzylaminopurine;

$\mathrm{HgCl} 2$ - Mercuric chloride;

IBA-Indole-3-Butyric Acid;

KIN-Kinetin;

MS-Murashige and Skoog;

NAA- $\alpha$-Naphthaleneacetic acid.

\section{Material and methods}

\subsection{Culture establishment}

The superior genotype of B. nutans were collected from the forest areas of Lal Mati, Sambalpur (Odisha, $21^{\circ} 28^{\prime} 0.7392^{\prime \prime} \mathrm{N}: 83^{\circ} 58^{\prime} 52.1976^{\prime \prime} \mathrm{E}$ ) and assembled in the germplasm bank of the institute. The nodal segment explants were collected in the year 2018 from young secondary branches of one year old clumps during summer (April) as this season was found to be best for bud break ${ }^{1}$. The nodal segments $(12-18 \mathrm{~mm})$ without leaf-sheaths were prepared from these shoots and washed for 10 min with $0.1 \mathrm{x}$ diluted aqueous solution of Dettol ${ }^{\circledR}$, an antiseptic liquid detergent (Avalon Cosmetics Pvt. Ltd., Sirmour, India). The explants were made free from Dettol ${ }^{\circledR}$ foam by continuous washings with distilled water and treated thereafter for half an hour with $0.2 \%$ aqueous solution of Bavistin, a systemic carbendazim fungicide (BASF India Ltd, Mumbai, India). Under aseptic condition, the fungicide treated explants were given a quick dip for $20 \mathrm{sec}$ in $70 \%$ ethyl alcohol before being administered $0.1 \%$ of aqueous mercuric chloride $\left(\mathrm{HgCl}_{2}\right)$ solution or 10 min. The explants were rinsed 4-5 times with sterile distilled water to remove traces of $\mathrm{HgCl}_{2}$.

The disinfected explants were initiated on MS (Murashige \& Skoogs ${ }^{5}$ ) semi-solid (0.8 \% agar) medium enriched with 3 $\%$ sucrose and $10 \mu \mathrm{M}$ BA in $2.5 \mathrm{~cm}$ x $15 \mathrm{~cm}$ culture tubes (Borosil, India). The axillary bud break started from third week onward (Fig 1a). The axillary shoots for in vitro multiplication became available only after fifth week and were subsequently maintained through ten subculture cycles each of 15 days on MS liquid medium supplemented with 10 $\mu \mathrm{M}$ BA before being utilized for the present investigation.

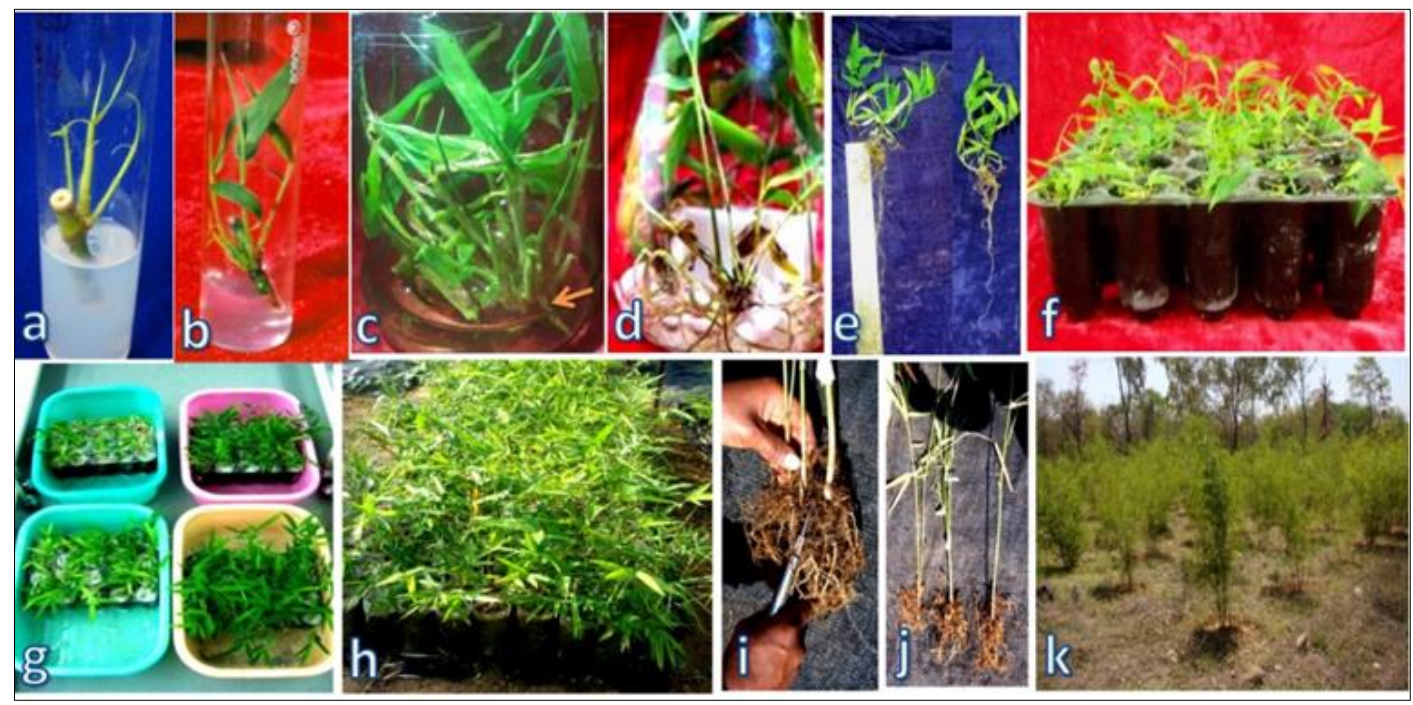

Figure 1 Acceleration of in vitro propagation of $B$. nutans: (a) initiation of axillary bud from nodal segment after third week of inoculation; (b) maximum shoot initiation on the medium enriched with $10 \mu \mathrm{M}$ BA with rhizome formation; (c) maximum shoot multiplication on the medium with $10 \mu \mathrm{M}$ BA $+7 \mu \mathrm{M} N A A$; (d) maximum rooting on medium supplemented with $30 \mu \mathrm{M}$ NAA; (e) in vitro raised tender plantlets ready for hardening; (f) plantlets transferred to root trainer for in vitro hardening; (g) transfer of plantlets to semi controlled conditions of shade house; (h) transfer of plantlets to polythene bags; (i-j) optimization of propagation through macroproliferation; (k) six month old plants transferred to the field 


\subsection{In vitro shoot multiplication}

A propagule (cluster of two axillary shoots) was excised and inoculated on MS liquid medium supplemented with different concentrations of BA $(10,20$, and $30 \mu \mathrm{M})$ in combinations with NAA $(2.5,5.0$ and $7.0 \mu \mathrm{M})$. The rate of shoot multiplication (ratio of shoot number to initial shoot number) was determined after 15 days of inoculation. On the basis of prolific shoot multiplication obtained in Pseudoxytenanthera stocksii ${ }^{6}$ and Dendrocalamus hamiltonii ${ }^{7}$, the combination of BA and NAA was also investigated for shoot multiplication in B. nutans.

\subsection{Rooting}

For invitro adventitious rooting a propagule of 2 shoots $(>2.0 \mathrm{~cm}$ length) were harvested from the cultures available after completion of multiplication experiment and inoculated on $1 / 2$ MS liquid medium supplemented with 20, 30 and $40 \mu \mathrm{M}$ NAA. The observation on rooting and associated parameters viz., root number and root length were recorded after 28 days.

\subsection{Culture condition and statistical analysis}

The ready-to-use salts of MS medium and phytohormones used for preparation of culture medium were obtained from Qualigens Pvt. Ltd., India. The $\mathrm{pH}$ of the medium was adjusted to 5.8 before autoclaving for $15 \mathrm{~min}$ at $1.06 \mathrm{~kg} \mathrm{~cm}^{-2}(121$ ${ }^{\circ} \mathrm{C}$ ). Each explant was cultured in a $2.5 \mathrm{~cm} \times 15.0 \mathrm{~cm}$ glass tube containing $10 \mathrm{ml}$ sterilized semi-solid medium for culture initiation and $150 \mathrm{ml}$ conical flasks containing $25 \mathrm{ml}$ liquid medium and ' $\mathrm{M}$ ' shape support made from Whatman ${ }^{\circledR}$ filter paper (NM Scientific Company, Mumbai, India) for in vitro shoot multiplication and rooting experiments. The cultures were incubated at $25 \pm 2{ }^{\circ} \mathrm{C}$ under 16 hillumination with fluorescent light (approx. $45 \mu \mathrm{Mol} \mathrm{m}^{-2} \mathrm{~s}^{-1}$ ) (Philips India Limited, Mumbai). The experiments comprising three replicates each of ten-single propagule-flasks were repeated twice. The data recorded for in vitro shoot multiplication and rooting were subjected to one-way analysis of variance, using SX statistical package. The significance of the data was ascertained by F-test and the Least Significant Difference values at $P=0.05\left(\mathrm{LSD}_{0.05}\right)$ computed for comparing means of various treatments ${ }^{8}$.

\subsection{Hardening and transplantation}

A two-step hardening procedure for hardening of in vitro raised plantlets was followed. Firstly, the plantlets were deflasked and washed in running tap water thoroughly so as to remove adhered medium from the surface of plantlets followed by washings with $0.2 \%(\mathrm{w} / \mathrm{v})$ Bavistin and tap water. The washed plantlets were transferred to root trainers comprising 25 cells each of 150 cc (Neevedita Plastic Industries, Nagpur, India), filled with a mixture of autoclaved soilrite: compost (1:1). The planted root trainers shifted to plastic tray filled with half strength of iron free MS salts covered with perforated transparent polythene sheet and maintained at $25 \pm 2{ }^{\circ} \mathrm{C}$ under $16 \mathrm{~h}$ photoperiod for in vitro hardening for an acclimatization period of 2-3 weeks until new leaves had emerged. Secondly, the plantlets were transferred to shade house and maintained for 2 weeks for ex vitro hardening and transplanted in to polythene bags containing soil: sand: farmyard manure (1:1:1) in the shade house condition for $1 \frac{1 / 2}{2}$ to 2 months receiving irrigation on alternate days and spray of $1 / 2$ MS solution once in 15 days.

\subsection{Macroproliferation and field transfer}

During the acclimatization process, the in vivo rhizome formation was observed after an approximate four months of growth. The hardened plants having 3-4 tillers intact with rhizomes and roots were carefully removed from the polybags. Each proliferated tiller along with some rhizome and roots was separated to act as a propagule and planted in fresh polythene bags of $22 \times 30 \mathrm{~cm}$ size filled with soil: sand: farmyard manure (1:1:1) and initially supplied with 100 ppm urea and maintained in shade house. The hardened plants were field transfer in the month of July and field survival was recorded after six months.

\section{Results}

\subsection{Culture establishment}

Using the disinfection method described in "Method" section, we recorded optimum $90 \%$ aseptic cultures in the medium supplemented simply with $10 \mu \mathrm{M}$ BA which resulted in $100 \%$ bud break after 8-10 days of inoculation (data not shown). The concentration of $10 \mu \mathrm{M}$ BA significantly impacted on shoot initiation and scored 7-8 numbers of axillary shoots after $5^{\text {th }}$ week (Fig 1b). 


\subsection{Shoot regeneration}

A single propagule inoculated on MS liquid medium supplemented with different concentrations of BA in combinations with NAA was reported with marked effect. The synergism of lower concentration of BA $10 \mu \mathrm{M}$ and higher concentration of NAA $7 \mu$ M was reported to increase significantly higher shoot regeneration registered with the maximum of 14.5 fold shoot multiplication rate (Fig 1c) followed by 5 fold multiplication rate in combinations with $10 \mu \mathrm{M} \mathrm{BA}+5 \mu \mathrm{M}$ NAA which were significantly higher than any other combinations (Fig 2). Besides, treatment of $10 \mu \mathrm{M}$ BA supplemented with $5 \mu \mathrm{M}$ and $7 \mu \mathrm{M}$ was also statistically different from each other. However, shoot length was recorded statistically non-significant in all combinations of BA and NAA.

Interestingly, in vitro rhizome formation occurred in the culture medium supplemented with $10 \mu \mathrm{M} \mathrm{BA}+7 \mu \mathrm{M}$ NAA in about $15 \%$ of the cultures (as depicted by an arrow in Fig 1c). The occurrence of in vitro rhizome formation was increased with increasing number of subculture passages. Similar to the nature, in vitro rhizome also supported the shoot formation and improved the overall health of the shoot cultures. Importantly, it is also reported in the highest rate of root regeneration in various bamboo species, therefore, such cultures were not utilized for in vitro rooting study.

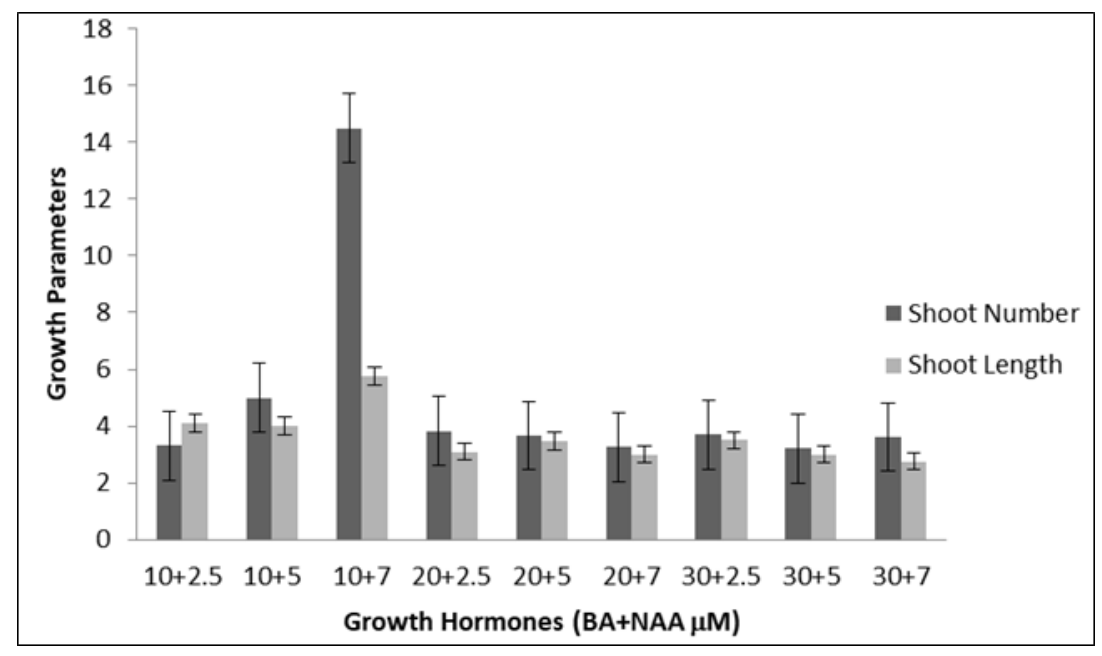

Figure 2 Interaction effect of BA and NAA on shoot regeneration of B. nutans

\subsection{Rooting}

The root initiation was started after $2^{\text {nd }}$ week of inoculation and continued till $4^{\text {th }}$ week. The cluster of 2-3 shoots inoculated in the medium with $30 \mu \mathrm{M}$ NAA yielded maximum rooting $(100 \%)$ within 4 weeks (Fig 1d) which was significantly higher than other two concentrations of NAA which produced at par rooting (Fig 3). The root number was not influenced by the different concentrations of NAA, however, $30 \mu \mathrm{M}$ NAA reported with significantly higher root length (Fig 1e).

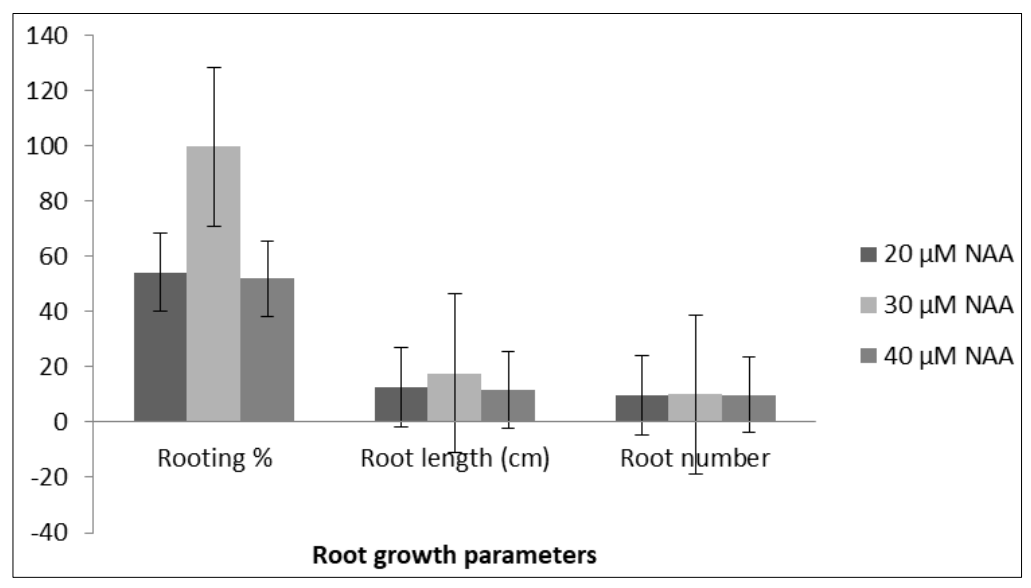

Figure 3 Effect of doses of NAA $(\mu \mathrm{M})$ on root regeneration of B.nutans 


\subsection{Hardening, macroproliferation and field transplantation}

To optimize the hardening procedure, two-step hardening procedure following gradual exposure of in vitro raised tender plantletsto (i) controlled conditions of culture room for 2-3 weeks in root trainers (Fig 1f) and (ii) semicontrolled conditions of shade house for 2 weeks produced $100 \%$ healthy acclimatized plantlets (Fig 1g), which exhibited $100 \%$ survival three months after transfer to polythene bags (Fig. 1h). The hardened plantlets were subjected to macroproliferation which registered 3 numbers of plants from a single hardened plant within after 4 months (Fig ij). The plants transferred to field in the month of July recorded with $100 \%$ survival showing excellent growth with new shoot recruitment after six month of transfer (Fig 1k).

\section{Discussion}

\subsection{Culture establishment}

For culture establishment from nodal explants of $B$. nutans, BA was used routinely by various investigators. The pronounced effect of BA is supported by Yadav et al. ${ }^{1}$ in B. nutans who used $10 \mu \mathrm{M}$ BA but with combination of IAA. Further, Negi \& Saxena ${ }^{2}$ also reported morphogenic response of nodal segment explants of $B$. nutans in the medium with $\mathrm{BA}$ and additional supplementation of Kinetin. On the basis of these published reports, we used single concentration of $\mathrm{BA}(10 \mu \mathrm{M})$ for culture establishment which is compatible with previous investigations and reported induction of fairly sufficient number of the axillary shoots and economized and improvised the shoot initiation of $B$. nutans from nodal segments.

\subsection{Shoot regeneration}

Our results show that the combined presence of BA and NAA in the MS medium stimulated the growth and multiplication of $B$. nutans shoots. The similar synergistic effect of BA-NAA has been reported by Sanjaya et al. ${ }^{6}$ who achieved $125-150$ shoots within 45-50 day in Pseudooxytenanthera stoksii. Similarly, Agnihotri et al. ${ }^{7}$ also reported 20 -fold multiplication rate in Dendrocalamus hamiltonii from field grown clumps. These remarkable results encouraged us to use the synergism of BA+NAA in B. nutans too. Our result exhibited that the combined effect of BA and NAA in the MS medium excelled the shoot multiplication rate by 4.5, 4.8 and 1.31 times than Yadav et al. ${ }^{1}$, Negi \&Interaction effect of BA and NAA on shoot regeneration of B. nutans Saxena ${ }^{2}$ and Sahrma \& Sarma ${ }^{3}$ respectively in B. nutans which may be attributed to collection of explants from superior genotypes and phytohormone amendments of BA+NAA interaction which was never explored for B. nutans. Similar to shoot multiplication, the combination of $10 \mu \mathrm{M}$ BA and $7 \mu \mathrm{M}$ NAA was also registered with the maximum shoot length which was significantly higher than any other combinations. This result is in accordance with the studies on Gigantochloa atroviolacea ${ }^{9}$ where increase in BAP concentration, reduced the number of shoots. A reason of the positive effect of auxin in the culture medium is that it nullifies the effect of higher cytokinins ${ }^{10}$. A cyokinin /auxin combination has earlier proved to be efficient for in vitro shoot proliferation in Pseudoxytenanthera stocksii ${ }^{6}$, Thamnocalamusspathiflorus ${ }^{11}$ and Bambusa nutans ${ }^{1}$.

In nature, $B$. nutans is a sympodial bamboo with well-developed root with rhizome ${ }^{12}$ which is notably different from the roots with thick wall bundle sheath fibers and layer structure near the pith hole and allows a greater storage potential and serve as an important adaptation to dry conditions ${ }^{13}$. Similar to the nature, we observed in vitro rhizome formation in shoot cultures as depicted by an arrow in Fig 1c, possibly due to the interaction between BA and NAA, which supports and improves the overall health of the shoots. In corroboration with the present finding, in vitro rhizome formation had been reported in B. tulda ${ }^{14}$ due to photohormonal amendments and due to presence of sucrose in Dendrocalamus asper and D. memberanaceus ${ }^{15}$.

\subsection{Rooting}

The propagules inoculated in the 1/2 MS basal medium supplemented with $30 \mu \mathrm{M}$ NAA produced optimal rooting within 4 weeks, which was significantly higher than other concentrations. The benchmark of $100 \%$ in vitro rooting was achieved in the present investigation which is in corroboration with the earlier report of Negi \&Saxena ${ }^{2}$ who also scored the similar results working with the same species, but engrossed with various steps of phytohormonal amendments into the culture medium and fails to economize the rooting procedure. Sharma \& Sarma ${ }^{3}$ also enriched the rooting medium with higher concentration of three types of auxins and reported $90 \%$ rooting in B. nutans. However, Yadav et al. ${ }^{1}$ used considerably lower concentration of NAA and reported $60 \%$ rooting in B. nutans. The present investigation overrides these earlier reports of in vitro rooting in B. nutans with optimum rooting success of $100 \%$ using only one source of auxin and this way economized and up scaled the existing procedures of in vitro rooting. 


\subsection{Hardening, macroproliferation and field transplantation}

To optimize the hardening procedure, two-step hardening procedure following gradual exposure of in vitro raised tender plantlets (Fig 1e) to (i) controlled conditions of culture room for 2-3 weeks in root trainers (Fig 1f) and (ii) semi controlled conditions of shade house for 2 weeksproduced $100 \%$ healthy acclimatized plantlets (Fig $1 \mathrm{~g}$ ), which exhibited $100 \%$ survival three months after transfer to polythene bags (Fig. $1 \mathrm{~h}$ ). The plants were supposed to undergo for macroproliferation which had successfully applied to many bamboo species $16,17,18$ and reported to produce 2-3 fold multiplication rate within span of 6-9 months. As compared to these reports, three fold multiplication was registered after 4 months (Fig i-j) and the reason for obtaining increased number of tiller in shorter span is probably due to the mode of propagation in the present study where large number of adventitious bud initials present in the tiller of micropropagated plants which resulted in promotion of vegetative growth. This report is also corroborated with the finding of Mishra et al. ${ }^{19}$ who obtained 3 number of tiller within 6 months using tissue culture raised B. tulda. The plantlets transferred to field in the month of July recorded with $100 \%$ survival showing excellent growth with new shoot recruitment after six month of transfer (Fig 1k)

\section{Conclusion}

The study aimed to upscale and refine the existing micropropagation protocols through in vitro axillary branching of field-grown superior genotype of B. nutans collected form Odisha state. An efficient method was developed for clonal propagation of $B$. nutans registering maximum shoot multiplication and rooting employing phytohormonal amendments and maximum hardening success. The survival of the plants in the field condition makes this protocol amenable to meet the growing demand for true-to-type, disease-free and quality planting material of selected genotype of B. nutans.

\section{Compliance with ethical standards}

\section{Acknowledgments}

The funding received from National Authority CAMPA (Compensatory Afforestation Planning and Fund, Ministry of Environment, Forest and Climate Change, New Delhi, India under AICRP-2 (Bamboo) for carrying out the experiments and fellowship paid to JPM and MM (Junior Project Fellow) is gratefully acknowledged.

\section{Disclosure of conflict of interest}

The authors have no conflicts of interest to declare. All authors have seen and agree with the contents of the manuscript and there is no financial interest to report. We certify that the submission is original work and is not under review at any other publication.

\section{References}

[1] Yadav S, Patel P, Shirin F, Mishra Y, Ansari SA. In vitro clonal propagation of 10-year-old clumps of Bambusa nutans. J Bamboo and Rattan.2008;7: 201-210.

[2] Negi D, Saxena S. In vitro propagation of Bambusa nutans Wall. Ex Munro through axillary shoot proliferation. Plant Biotechnol Rep.2011;5: 35-43.

[3] Sharma P, Sarma KP. In vitro propagation of Bambusa nutan in commercial scale in Assam India. J Environ ResDev.2014;9: 348-355.

[4] Mudoi KD, Saikia SP, Borthakur M. Effect of nodal positions, seasonal variations, shoot clump and growth regulators on micropropagation of commercially important bamboo, Bambusa nutans Wall. Ex. Munro.Afr J Biotechnol.2014;13: 1961-1972.

[5] Murashige T, Skoog F. A revised medium for rapid growth and bioassays with tobacco tissue culture. Physiol Plant. 1962;15: 473-497.

[6] Sanjaya, Rathore TS, Ravishankar RV. Micropropagation of Pseudooxytenanthera stoksii munro. In Vitro Cell Dev Boil- Plan.2005;41: 333-337.

[7] Agnihotri AK, Mishra J, Nandi SK. Improved in vitro shoot multiplication and rooting of Dendrocala mushamiltonii Nees et Arn. Ex Munro: Production of genetically uniform plants and field evaluation. ActaPhysiol Plant.2009;31: 961-967. 
[8] Gomez KA, Gomez AA. Statistical Procedures for Agricultural Research. John Willey and Sons, New York. 1984; 643-645.

[9] Bisht P, Pant M, Kant A. In vitro propagation of Gigantochloa atroviolaceae Widjaja through nodal explants. J American Sci.2010;6: 1019-1025.

[10] Hu CY, Wang PJ. Meristem shoot tip and bud culture. In: Handbook of Plant Cell Culture, Vol. I, Eds. Evans DA, Sharp WR, Ammirato PV, Yamada Y. Ma cmillan Publishing Company, New York.1983; 177-227.

[11] Bag N, Chanda S, Palni LMS, Nandi SK. Micropropagation of Devringal (Thamnocalamus spathiflorus (Trin) Munro a temperate bamboo and comparison between in vitro propagated plants and seedlings. Plant Science.2000;156:125-135.

[12] Tewari DN. A monograph on bamboo. International Book Distributors, Dehra Dun. 1992.

[13] Ryoyo I, Hisashi M, Nobuhiko K. Rhizome and root anatomy of moso bamboo (Phyllostachys pubescens) observed with scanning electron microscopy. J Wood Sci.2015;61: 431-437.

[14] Waikhom SV, Louis B. An effective protocol for micropropagation of edible bamboo species (Bambusatulda and Melocanna baccifera) through Nodal Culture. The Sci World J. 2014.

[15] Nirmala C, Ali AH, Badal T. De novo organogenesis in the form of rhizome in Dendrocalamus asper and $D$. membranaceus. Curr Sci.2011;100: 468-470.

[16] Banik RL. Techniques of bamboo propagation with special reference to pre-rooted and pre-rhizomed branch cuttings and tissue culture (Ed.Rao, AN). Canada: IDRC.1987; 160-169.

[17] Kumar A, Gupta BB, Negi DS. Vegetative propagation of Dendrocalamus strictus through macroproliferation II. Ind For.1988;117: 621-623.

[18] Dubey RM, Das PS, Choudhary R. An investigation in to macroproliferation of some selected species of Assam. Ind For.2008;134:367-378.

[19] Mishra Y, Patel P, Ansari, SA. Acclimatization and macro proliferation of micro propagated plants of Bambusa tulda Roxb. Asian J of Exp Bio Sci.2011;2:498-501. 